\title{
EDITORIAL
}

Kyung Chun Kim $\cdot$ Sang Joon Lee

\section{The 14th International Symposium on Flow Visualization, ISFV14}

Published online: 29 July 2011

(C) The Visualization Society of Japan 2011

Guest Editors
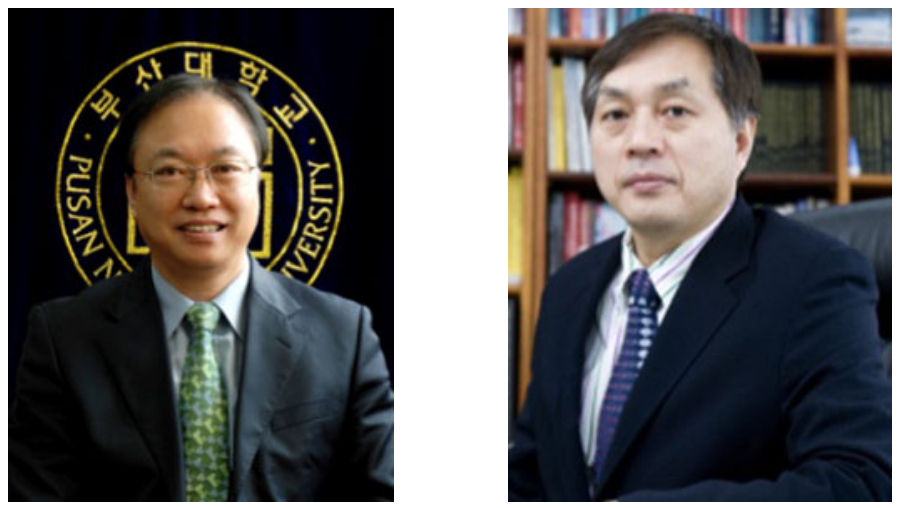

The 14th International Symposium on Flow Visualization (ISFV14) was held in Daegu, Korea, on 21-24 June 2010. The number of participants was 304 from 17 countries. The state of arts in many aspects of flow visualization was presented and discussed, and the number of papers presented was 243 from 19 countries. Two special lectures and four invited lectures, 48 paper sessions, and one poster session were held in five session rooms and in a lobby for 4 days. Among 48 paper sessions, the sessions of "biological flows", "micro/nano fluidics", "PIV/PTV", "compressible and sonic flows" were receiving large attention from ISFV14 participants. Special events such as awarding "The Asanuma Award" and "The Leonardo Da Vinci Award" to the prominent contributors were endowed. Photo and movie awards were given to three scientists for their excellences in flow visualizations.

Sixteen papers were selected by the Scientific Committee of ISFV14. After the standard peer review process of Journal of Visualization (JOV), 11 papers were finally accepted for publication. We wish to thank the editors and reviewers of JOV for making it possible to publish this special issue from ISFV14. We also thank to the authors for their careful and insightful work and cooperation in the preparation of revised papers. It will be our pleasure if readers appreciate the hot topics in flow visualization research as a result of this special issue. We also hope the progress in flow visualization will create new research fields. The 15th International Symposium on Flow Visualization will be held in Minsk, Belarus in 2012. We would like to express sincere thanks to the staff at Springer Verlag for their kind support.

K. C. Kim (ه)

Pusan National University, Pusan, Korea

E-mail: kckim@pusan.ac.kr

S. J. Lee

Pohang University of Science and Technology, Pohang, Korea 